\title{
Current Advances in Noncoding RNA Relevant to Epigenetic Mechanisms
}

\author{
Prabhu Mathiyalagan • Abdul Waheed Khan • \\ Xiao-Jun Du • Assam El-Osta
}

Published online: 25 February 2015

(C) Springer International Publishing AG 2015

\begin{abstract}
The human genome regulates dynamic patterns of transcript expression and while studies in recent years by the Encyclopedia of DNA Elements (ENCODE) consortium have shown the remarkable complexity of pervasive transcription, it is estimated that less than $2 \%$ of the genome codes for proteins. Multiple lines of experimental evidence now highlight the functional importance of noncoding RNAs (ncRNAs) that serve to control transcription that underlie development and homeostatic control in metazoans. An emerging theme is the modulation of transcription factor binding governed by ncRNA-chromatin interactions. Some of the recent discoveries of contractile function in the heart implicate novel roles for long ncRNAs (lncRNAs), including the primary microRNA-208b (Pri-miR-208b) as well as antisense $\beta$-MHC (AS $\beta$-MHC). As such, this review will focus on the signaling and regulatory functions of ncRNAs that ensure homeostasis of mammalian myosin motor protein expression and cardiovascular disease.
\end{abstract}

This article is part of the Topical Collection on Epigenetics

P. Mathiyalagan · A. W. Khan · X.-J. Du • A. El-Osta

Baker IDI Heart and Diabetes Institute, The Alfred Medical Research

and Education Precinct, Melbourne, VIC 3004, Australia

P. Mathiyalagan

e-mail: pmathiyalagan@bakeridi.edu.au

A. W. Khan

e-mail: abdulwaheed.khan@bakeridi.edu.au

X.-J. Du

e-mail: xiao-jun.du@bakeridi.edu.au

A. W. Khan · A. El-Osta

Department of Pathology, The University of Melbourne,

Parkville, Victoria, Australia

A. El-Osta $(\square)$

Faculty of Medicine, Monash University, Victoria, Australia

e-mail: assam.el-osta@bakeridi.edu.au
Keywords Epigenetics $\cdot$ Noncoding RNA $\cdot$ MicroRNA . Gene regulation $\cdot$ Chromatin modifications $\cdot$ Heart

\section{Introduction}

The Human Genome Project (HGP) is one of the largest collaborative programs that has uncovered an enormous wealth of information regarding the genetic blueprint; however, it has also raised significant debate on gene function. Surprisingly, the estimated number of protein-coding genes in the human genome, approximately 20,000 is in fact comparable with biologically less complex organisms [1]. The striking biological complexity in humans is thought to have arisen from nonprotein coding (noncoding) sequences that comprise almost $98 \%$ of the total genomic DNA in humans [2]. The contribution of noncoding DNA to human complexity is further exemplified by recent genome-wide association studies (GWAS) that revealed that the majority ( $93 \%$ ) of disease-associated risk loci are located in noncoding DNA sequences [3-5].

The ENCyclopedia of DNA Elements (ENCODE) project led to the identification of functional elements within noncoding DNA regions [6]. One of the major conclusions from ENCODE was that almost $90 \%$ of noncoding DNA in the human genome is transcribed, only $1-2 \%$ (mRNA) of transcripts encode proteins and the remaining $98 \%$ represent noncoding RNAs (ncRNAs) [7-9]. The unexpected pervasive transcription in the human genome was initially challenged and regarded as transcriptional noise or a technical artifact; however, follow-up studies independently validated the original experimental findings $[10,11,12 \bullet \bullet]$. The challenge now is to generate a complete annotation of the ncRNA transcriptome and begin interrogating the functional relevance of ncRNAs in human health and disease. To this end, loss-offunction approaches both in vitro and in vivo are providing initial evidence for critical roles of long ncRNAs (lncRNAs) 
in development as well as chromatin regulation $[13 \bullet \bullet, 14 \bullet$, $15 \bullet \bullet, 16,17 \bullet]$.

In this article, we describe some of the latest developments in ncRNA-mediated epigenetic regulation and highlight specific roles for ncRNAs in the maintenance of histone modifications, DNA methylation, and chromatin architecture. We provide specific examples from recent studies implicating lncRNAs in epigenetic regulation of cardiac gene expression. We also explore potential therapeutic opportunities associated with the treatment of heart failure.

\section{Noncoding RNAs and Chromatin}

Noncoding RNAs do not have open reading frames (ORF) required for protein coding. Based on nucleotide (nt) length, ncRNAs are classified as small $(<200 \mathrm{nt})$ or long (>200 nt) ncRNAs. Small ncRNAs include microRNAs (miR), whose estimated number of genes is currently at 2000 in the human genome [18]. In contrast, IncRNA genes are estimated to be over 60,000 and show regulation in a development-specific manner [19]. About $90 \%$ of human genes undergo alternative splicing and at least 100,000 alternatively transcribed lncRNAs have been identified to date $[19,20]$. The RNA output of the genome is plethora of antisense RNA (asRNA) while some asRNA have been proposed to have regulatory functions [21]. While biological roles for regulatory RNAs have been described for several decades, the majority of ncRNA functions were limited to post-transcriptional processing of messenger RNA (mRNA) through spliceosome and ribosome machineries.

Chromatin remodeling is fundamental to several nuclear processes, including DNA replication and repair as well as gene regulation [22, 23], and RNA has long been thought to directly contribute to chromatin architecture. However, a relative paucity in techniques posed significant challenges in exploring RNA-chromatin interactions [24]. Over the past few years, this has changed: rapid developments in chromatin-based assays coupled with nucleic acid sequencing technologies have deepened our understanding of ncRNA mechanisms of epigenetic regulation of chromatin [25].

\section{Developmental Expression of NcRNAs}

Spatial and temporal control of gene expression is fundamental in the course of development and differentiation. LncRNA genes show development-specific expression pattern and required for the maintenance of pluripotency in embryonic stem cells $[15 \bullet \cdot$. Perturbations to $\operatorname{lncRNA}$ expression affect transcription factor binding and global gene expression patterns required for maintaining pluripotency $[15 \bullet \cdot]$. The two IncRNAs BRAVEHEART and FENDRR are critical regulators of mouse heart development $[16,17 \cdot]$. Depletion of BRAVEHEART in mouse embryonic stem cells impairs cardiomyocyte differentiation and contractility, whereas FENDRR is required for heart and body wall development $[16,17 \bullet]$. Both BRAVEHEART and FENDRR coordinate actions by interactions with the chromatin complex [16, 17•]. Recent studies also implicate novel lncRNAs functioning as molecular scaffolds that orchestrate transcription factor binding essential for neuronal differentiation [26]. Together, these recent data indicate lncRNAs as key regulators of stem cell pluripotency as well as determinants of lineage specification during development.

\section{Modes of Action}

To date, the best understood ncRNA mechanism of epigenetic regulation is the RNA-Induced Silencing Complex (RISC)mediated post-transcriptional gene silencing by miRs [27]. MicroRNA genes are transcribed by RNA polymerase II as primary microRNA transcripts (Pri-miR), which are processed to precursor (pre-miR) and mature microRNAs (miR) by RNase III enzymes, DROSHA and DICER, respectively (Fig. 1a) [37]. MicroRNAs base pair with mRNAs of protein-coding genes primarily in the cytoplasm and the miR-mRNA interaction initiates post-transcriptional gene silencing by promoting mRNA degradation or translational inhibition (Fig. 1a). Nevertheless, ncRNA interactions with mRNA can regulate translation both positively and negatively. Besides roles in posttranscriptional gene regulation by miRs in cytoplasm, miRs are often detected inside nucleus and associated with transcriptional regulation (Fig. 1b) [28]. In addition, since miRs are detectable in the circulating blood stream they are thought to regulate gene expression at distal tissues and may represent useful clinical biomarkers (Fig. 1c) [29].

LncRNAs are dynamically regulated and often detected at low levels. The majority of $\operatorname{lncRNAs}$ are retained in the nucleus where they regulate transcription in cis or in trans. Cisacting ncRNAs affect the expression of target genes near the same genomic locus (Fig. 1d, e). Trans-acting ncRNAs can regulate target gene expression at distal domains (Fig. 1f). In this way trans-acting lncRNAs can regulate patterns of gene expression using several different mechanisms. Firstly, lncRNAs can serve as signals to chromatin modifiers such as the Polycomb Repressive Complex 2 (PRC2), which mediates H3K27me3 and gene silencing [14•]. Secondly, lncRNAs are thought to bind DNA and establish stable RNA-DNA hybrid at promoters of target genes [33•, 38, 39•]. Both these mechanisms coordinate epigenetic changes to either repress or activate gene expression. Studies by our 


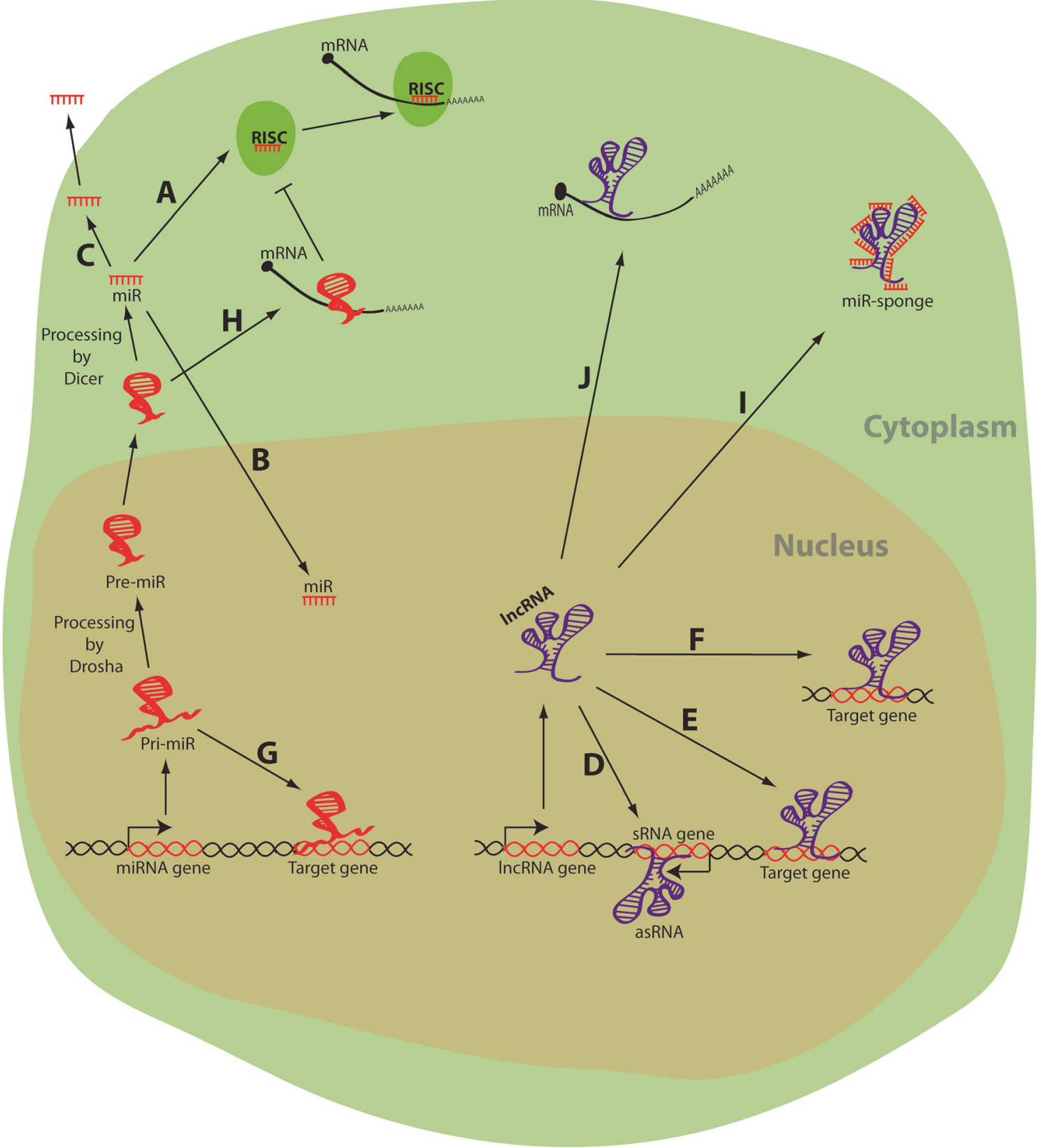

Fig. 1 Roles of ncRNAs in epigenetic regulation by transcriptional and post-transcriptional mechanisms. Noncoding RNAs identified as regulators of gene expression from gene transcription to mRNA translation are depicted. $A$ Post-transcriptional mRNA regulation by miR via RISC pathway [27]. $B$ Nuclear import and miR-directed intranuclear functions [28]. $C$ Extracellular signaling by miRs entering into blood [29]. $D$ Regulation of sense transcription by asRNA [30]. $E$ Transcriptional regulation by cis-acting lncRNAs [31••]. F Genome-

group reveal a novel mechanism of transcriptional regulation by an unprocessed primary microRNA transcript in the mouse heart (Fig. 1g). The primary microRNA-208b (pri-miR-208b) transcript binds DNA using a 34-nucleotide long recognition sequence that is enriched within promoters of key cardiac genes including the bi-directional promoter (bdP) of cardiac myosin heavy chain (MHC) genes [33•]. The pri-miR-208b wide transcriptional regulation by trans-acting lncRNAs [32]. $G$ Chromatin association and transcriptional regulation by pri-miR [33•]. $H$ Post-transcriptional mRNA regulation by pre-miR [34•]. I LncRNAs as miR-sponges [35]. $J$ Post-transcriptional mRNA regulation by cytoplasmic lncRNAs [36•]. mRNA messenger RNA, IncRNA long noncoding RNA, $m i R$ microRNA, Pri-miR primary microRNA, Pre$m i R$ precursor microRNA, $s R N A$ sense RNA (mRNA), as $R N A$ antisense RNA, RISC RNA-induced silencing complex

localizes within nucleus and regulates epigenetic silencing of genes by binding to EZH2 component of PRC2 in the heart [33•]. More recent work suggests a novel post-transcriptional regulation of miR-activity by competing pre-miR transcripts (Fig. 1h) [34•]. For example, binding of pre-miR-151 to E2F6 mRNA, which is a target of miR-151, interferes with RISCmiR-151 complex binding and increases E2F6 protein 
production (Fig. 1h). Post-transcriptional regulation of miRactivity can also be mediated by lncRNAs that function as miR-sponges [35]. LncRNAs enriched for complementary sequences to miRs can sequestrate miRs from mRNA target recognition (Fig. 1i). Finally, the lncRNA TINCR controls somatic cell differentiation by binding to mRNAs of key differentiation genes in cytoplasm and increases mRNA stability and protein production [36 $6^{\circ}$. TINCR binds to mRNAs directly using a 25-nucleotide long "TINCR box" motif that is enriched in mRNAs of differentiation genes (Fig. 1j).

\section{Regulation of Histone Modifications}

Transcriptional control is fundamental to developmental regulation and tissue-specific gene expression. Eukaryotic RNA polymerase II-mediated transcription involves complex interactions of DNA-binding transcription factors as well as coregulatory proteins that activate or suppress the expression of genes. Co-regulatory factors include enzymes that modify chromatin such as histone methyltransferase and acetyltransferase activities. More than 100 post-translational chemical modifications to lysine tails of histone core proteins have been characterized in important nuclear functions [40]. For example, histone $\mathrm{H} 3$ is subject to acetylation at lysine positions 9 and $14(\mathrm{H} 3 \mathrm{~K} 9 / \mathrm{K} 14 \mathrm{ac})$ as well as methylation of lysine at positions 4 (H3K4me), 9 (H3K9me), and 27 (H3K27me). These marks coincide with transcriptional status: $\mathrm{H} 3 \mathrm{~K} 27 \mathrm{me} 3$ and H3K9me3 modifications are detected at transcriptionally silent chromatin, whereas $\mathrm{H} 3 \mathrm{~K} 9 / 14 \mathrm{ac}$ and H3K4me3 marks associate with transcriptionally active genes [40]. Diseases such as cancer and heart failure are often associated with aberrant expression and/or activity of histonemodifying enzymes [23, 41]. The challenge now is to precisely understand how histone modifiers locate their target genes. Recent studies have shown that IncRNA-dependent chromatin interactions can guide histone modifiers including the PRC2 and lysine-specific demethylase 1 (LSD1) complexes [14•, 42]. For example, the IncRNA HOTAIR suppresses genome-wide gene expression by binding to PRC2 and LSD1/CoREST/REST repressor complexes to coordinate $\mathrm{H} 3 \mathrm{~K} 27$ trimethylation as well as $\mathrm{H} 3 \mathrm{~K} 4$ demethylation on gene promoters [32, 42]. Similarly, in the developing mouse heart, the IncRNAs BRAVEHEART and FENDRR mediate transcriptional silencing by PRC2 [16, 17•]. FENDRR is also reported to associate with TrxG/MLL complex to mediate $\mathrm{H} 3 \mathrm{~K} 4$ methylation on promoters to activate gene expression [17•]. In a similar fashion, HOTTIP lncRNA binds the MLL family of $\mathrm{H} 3 \mathrm{~K} 4$ methyltransferase enzymes to activate transcription at the HOXA locus in human fibroblasts [43•]. Whether lncRNAs regulate disease-associated gene expression remains largely unknown, however, pri-miR-208b interaction with the $\mathrm{EZH} 2$ component of $\mathrm{PRC} 2$ regulates the expression of genes implicated in the failing heart [33•]. These recent experimental results place ncRNAs on the chromatin template to coordinate histone modifications implicated in regulating gene transcription.

\section{Regulation of DNA Methylation}

To date, the best-characterized epigenetic modification is the methylation of DNA at cytosine residue within the $\mathrm{CpG}$ dinucleotide sequence to form 5-methylcytosine. DNA methylation at gene promoters interferes with transcription factor binding and negatively regulates gene expression. While small RNA-directed DNA methylation has been documented for decades in plants, little is known in metazoans [39•, 44]. LncRNAs have been shown to directly bind DNA methyltransferases (DNMT), an example of this is the silencing of rRNA genes in human cells as well as the one mega-base KCNQ1 imprinted domain [39•, 44]. Long antisense RNAs such as KHPS1A and p15-AS have been shown to change promoter DNA methylation to regulate sense RNA expression. Whereas, KHPS1A promotes demethylation of the $S P H K 1$ promoter, the p15-AS transcript is associated with methylation of $p 15(C D K N 2 B)$ promoter in tumor cells [45, 46]. More recently, the extra-coding CEBPA IncRNA (ecCEBPA) has been shown to bind directly to DNMT1 and is implicated in gene-selective DNA demethylation [47••]. Detailed characterization of DNMT1-interacting RNAs revealed the stem-loop structure within RNA as well as the RNA-binding interface in close proximity to the catalytic domain of DNMT1, which is thought to interfere with DNA methylation [47••]. In addition to DNMT-interacting RNAs, several studies have shown IncRNA-dependent gene-specific binding for the transcriptional coregulator, methyl $\mathrm{CpG}$ binding protein 2 (MECP2) [48-50]. For example, the lncRNA EVF2 (DLX6AS) regulates DNA methylation across the enhancer of DLX genes to recruit MECP2 for gene silencing [49]. Work from our laboratory indicates novel MECP2interacting RNAs, including the Retinal noncoding RNA 3 (RNCR3), MALAT1, XIST, and KCNQ1OT1 in regulating brain-specific pattern of gene expression in mice [50]. Aberrant promoter DNA methylation is hallmark of tumor cells. Over expression of HOTAIR has been shown to drive tumorigenesis and promoter DNA methylation of the tumorsuppressor gene PTEN in models of laryngeal squamous cell carcinoma (LSCC) [51, 52]. Conversely, the lncRNA TCF21 antisense RNA including demethylation (TARID) has been shown to activate $T C F 21$ gene transcription by promoting DNA demethylation [53]. In cancer cells, TCF21 is subjected to promoter DNA methylation and epigenetic silencing [54]. Undoubtedly, deeper understanding of ncRNAs involved in regulation of DNA methylation can offer promising avenues to pharmacologically targeting ncRNAs to regulate gene 
expression implicated in diseases such as cancer and heart failure.

\section{Regulation of Chromatin Architecture}

Dosage compensation in females by X-chromosomal inactivation $(\mathrm{XCI})$ is a prototype of ncRNA-mediated epigenetic regulation [55]. The X-inactive-specific transcript (XIST) encoded on the X chromosome initiates XCI in female mammalian cells $[31 \bullet \cdot$. XIST spreads across one of the two X chromosomes in cis to initiate heterochromatin formation by $\mathrm{PRC} 2$ and H3K27me3-mediated epigenetic silencing [55]. Recent experiments by Engreitz et al. reveal mechanistic insights into XIST regulation [31••]. The authors identified a silencing domain that is critical for XIST localization at active sites of transcription across the inactive $\mathrm{X}$ chromosome [31・•]. For instance, XIST transcription results in accumulation of XIST RNA to bind active genes at distal X-chromosomal regions. The inactivation of active genes repositions XIST and remodels new X-chromosomal regions closer to the site of XIST transcription [31••]. Similarly, FIRRE lncRNA encoded on the $\mathrm{X}$ chromosome spreads across a 5-Megabase domain from the site of FIRRE transcription [56]. Unlike XIST, FIRRE is a trans-acting lncRNA that localizes at five distinct chromosomal locations that are spatially proximal to the FIRRE transcription site [56]. In an attempt to identify these regions, a strategy to characterize ncRNA domains was employed using chromatin isolation by RNA purification (dChIRP) to show a "three-fingered" ribonucleoprotein structure within the roX1 lncRNA transcript [57••]. Each roX1 RNA finger aids roX1 binding to male-specific lethal (MSL) protein complex and chromatin to mediate $\mathrm{X}$ chromosomewide dosage compensation in Drosophila melanogaster [57••]. The advent of dChIRP and other novel strategies will enable researchers to unravel the complex nature of RNAchromatin interactions associated with gene regulation mediated by epigenetic change.

\section{Recent Emergence of NcRNA-Mediated Epigenetic Regulation in the Heart}

Cardiomyocytes are terminally differentiated cells that are the primary determinants of heart muscle contractility. Precise regulation of gene expression in the heart is critical because cardiomyocyte gene deregulation can result in irreversible myocardial damage $[58,59]$. Recent studies highlight the importance of chromatin modifications in regulating patterns of gene expression in the heart [58,60-62]. Regulatory determinants include enzymes with acetylase and deacetylase activities as well as methyltransferase proteins, including SWI/SNF chromatin remodeling complex proteins such as BRG1 [23,
62-64]. Specifically, pharmacological histone deacetylase (HDAC) inhibition has proven beneficial in the preclinical treatment of heart failure [33•,65-67]. Among several chromatin modifiers in the heart are the EZH2 component of PRC2 and the ATPase-dependent BRG1 protein whose contributions to gene regulation in the heart have recently been described to involve ncRNA interactions $[16,17 \cdot, 33 \bullet, 68]$.

\section{Cardiac Expression of LncRNAs}

Endogenous natural antisense transcripts (NATs) from key contractile genes regulate sense mRNA transcription in the heart $[25,69]$. For example, antisense RNAs encoded by cardiac contractile genes regulate $\beta$-MHC and TROPONIN I mRNA translation [70, 71]. Deep sequencing of the mouse transcriptome of the failing heart recently identified novel lncRNAs of unknown function [72, 73]. The identification of LIPCAR lncRNA is considered a biomarker for heart failure [74]. Identified in plasma, LIPCAR expression increases at late stages of post-myocardial infarction (MI) and is further elevated with chronic heart failure [74]. For many years, the association of common variants within the chromosome 9p21 region with increased risk to coronary artery disease (CAD) and type 2 diabetes was poorly understood [75, 76]. However, the association of $9 \mathrm{p} 21$ with disease was later reported to involve the expression of lncRNAs [75, 76]. For instance, the 9p21 CAD risk interval flanks the lncRNA gene antisense noncoding RNA in the INK4 locus (ANRIL) whose expression is altered and thought to regulate two tumor-suppressor genes, $C D K N 2 A$ and $C D K N 2 B$, in individuals homozygous for the risk variant [77]. Mechanistic insights into lncRNA actions provide miR-sponge-like functions for cardiac lncRNAs. LncRNAs functioning as miR sponges sequester miRs from mRNA target recognition (Fig. 1i). Cardiac apoptosis-related lncRNA (CARL) suppresses stress-induced mitochondrial fission and apoptosis by sequestering miR-539 [35]. In a similar fashion, cardiac hypertrophy related factor (CHRF) lncRNA was shown to regulate miR-489 and cardiac hypertrophy by acting as miR-sponge [78].

\section{Cardiac Myosin Heavy Chain Gene Expression in the Heart}

Cardiac MHC genes, MYH6 ( $\alpha-M H C)$ and MYH7 ( $\beta-M H C)$, encode proteins that complex with myosin motor, which is the primary determinant responsible for myocardial contractility [79]. MHC proteins confer energy driven by ATP hydrolysis which is at least three times faster for $\alpha$-MHC than $\beta$-MHC [80]. In rodents, expression of $\beta$-MHC predominates during heart development whereas expression of $\alpha$-MHC predominates in adult hearts [79]. In adult human hearts, the 
expression of $\alpha$-MHC is approximately $15 \%$ of total MHC and the remaining constitutes $\beta$-MHC isoform [81]. One hallmark of cardiac hypertrophy and heart failure is decreased $\alpha$ MHC gene expression [82, 83]. In mouse hearts, cardiac hypertrophy is also associated with increased $\beta-M H C$ gene expression and thought to be disadvantageous [84]. While there is interest to attenuate the $\alpha$ - to $\beta$-MHC shift using pharmacological inhibitors, the mechanisms coordinating the regulation of MHC genes during cardiac hypertrophy remain poorly understood. The $\alpha-M H C$ and $\beta-M H C$ genes are organized in tandem on chromosome 14 [85]. In addition to mRNAs of myosin ATPase proteins, $\alpha-M H C$ and $\beta-M H C$ genes encode microRNAs, miR-208a and miR-208b, respectively. Together with $M Y H 7 B$-encoded miR-499, these three miRs comprise MyomiR family of miRNAs [86]. MiR-208a regulates expressions of miR-208b and miR-499 in the mouse heart [86]. Increased expression of $\beta-\mathrm{MHC}$ and miR-208b is hallmark of pathological cardiac hypertrophy and inhibition of miR208a reduces $\beta$-MHC and miR-208b expressions in preclinical models of heart failure [87]. Both miR-208a and miR-208b share a common seed sequence and predicted to target mRNAs of SOX6, PUR $\beta, S P 3$, THRAP1, MYOSTATIN, and GATA4 genes [86, 88]. Furthermore, it is not clear whether MyomiRs can mediate extracellular signaling by entering blood stream (Fig. 1c) [29]. For example, the levels of miR208b, miR-499, and miR-208a show up to 1600-, 100-, and 36 -fold increased plasma detection, respectively, in patients with acute myocardial infarction $[89,90]$.

\section{Myosin Family of LncRNAs}

The $\alpha$ - and $\beta$-MHC genes are separated by a 4.5 -kilobase intergenic region that comprises a bdP $[25,33 \bullet]$. The bdP transcribes a lincRNA, antisense $\beta$-MHC (AS $\beta$-MHC) in the direction opposite to $\beta$-MHC gene transcription. Cardiac expression of AS $\beta$-MHC was first reported in 1992 by Boheler et al. in rats [70]. Later, Luther et al. reported AS $\beta$ MHC expression in the human myocardium and proposed a role for AS $\beta$-MHC transcript in post-transcriptional regulation of sense mRNA ( $\beta$-MHC) [91]. Haddad et al. provided initial mechanistic insights on bdP regulation in hypothyroidic and diabetic hearts [92]. Indeed, the bdP responds to pressure overload induced by aortic-banding and the expression of AS $\beta$-MHC is downregulated in diabetic, hypothyroidic, and hypertrophic hearts [93-95]. Chromatin immunoprecipitation experiments in mouse left ventricles subjected to pressure overload indicate physical association between the PcGprotein Ezh2 and the pri-miR-208b transcript in epigenetic silencing of the bdP [33•]. The cardioprotection by pharmacological HDAC inhibition involves restoration of cardiac MHC gene expression to comparable healthy levels in hearts $[65,84]$. To test whether HDAC inhibition regulates AS $\beta$ -
MHC expression, we administered trichostatin A (TSA) in mouse models subjected to transverse aortic constriction (TAC) to induce pathological cardiac hypertrophy [33•]. Remarkably, TSA was able to restore the expression of AS $\beta$ MHC as well as suppress pathological $\beta$-MHC mRNA expression in hypertrophic hearts [33•]. The increased AS $\beta$ MHC expression is consistent with increased chromatin interaction [33•]. More recent evidence indicates alternatively spliced novel AS $\beta$-MHC variants originating from the MHC bdP region [68]. The suppression of AS $\beta$-MHC during cardiac hypertrophy has been shown to involve specific interactions of BRG1-HDAC-PARP corepressor at the bdP [68]. In turn, the AS $\beta$-MHC transcript physically associates with the chromatin remodeler BRG1 and prevents interaction of BRG1 at promoters of target genes, including $\alpha-M H C$ and $\beta$-MHC [68]. The AS $\beta$-MHC variant, Mhrt779 in mice is thought to be cardioprotective by mechanisms that involve direct association of AS $\beta$-MHC with BRG1 regulating pathological gene expression [68].

MicroRNA-208b is encoded within intron 31 of the cardiac $\beta-M H C$ gene and is among several intronic miRs that are expressed independent of host gene transcription [86, 96]. Recently, we have uncovered a novel mechanism of gene regulation by the pri-miR-208b transcript in the mouse heart (Fig. 1g) [33•]. Chromatin assays in hypertrophic left ventricles indicate pri-miR-208b interactions with the PcG-protein EZH2. HDAC inhibition by TSA attenuates interactions mediated by pri-miR-208b and EZH2 in regulating bdP of MHC genes in cardiac hypertrophy [33•]. This description of primary microRNA-mediated transcriptional regulation at the chromatin level is in addition to mature miRNA-mediated posttranscriptional regulation through RISC pathways in the cytoplasm. Taken together, these new results indicate lncRNAs as integral components of epigenetic regulation of gene expression in the heart $[33 \cdot, 68]$.

\section{Conclusion}

The majority of pharmacologically active compounds exhibit inhibitory actions on target proteins or pathways. However, compounds that can activate as well as repress specific pathways would be clinically advantageous. Since ncRNAs can regulate gene expression positively or negatively, ncRNA therapeutics offers tremendous opportunities to explore microRNA, chromatin-associated lncRNA and circular RNA mechanisms to willfully up- or down-regulated gene expression (Fig. 1). Targeting MyomiRs to treat cardiac hypertrophy and heart failure has proven promising in preclinical settings $[88,97]$. Whereas, optimization of miRNAs to the treatment of diseases, including cancer, heart failure, and neurodegenerative disorders have been relatively successful; the approach has fallen short of expectations primarily because of short 
sequence specificity and off-target functions. The intrinsic specificity of lncRNAs addresses off-target concerns making them ideal candidates for therapeutics. In addition to specific target recognition, the other unique feature of IncRNAs includes endogenous RISC-independent regulation of gene expression (Fig. 1). Circular RNAs or lncRNAs enriched for miR sequences can act as miRNA sponges and tether miRs from target mRNA recognition. This offers promise to induce protein production in disease states. Recently, pharmacological inhibition of the BDNF-AS transcript in mice using antagoNAT upregulated transcription of sense BDNF, a neurotrophin whose activation is thought to be beneficial in treatment of neurodegeneration [98•]. Together, we envisage that the successful clinical translation of ncRNA therapeutics holds exciting technical and conceptual challenges that warrant rapid developments in chromatin-based assays coupled with nucleic acid sequencing technologies.

\section{Compliance with Ethics Guidelines}

Conflict of Interest Baker IDI Heart and Diabetes Institute, The Alfred Medical Research and Education Precinct has received grant money from NHMRC that is relevant to this work. Prabhu Mathiyalagan, Abdul Waheed Khan, Xiao-Jun Du, and Assam El-Osta $(\mathrm{PhD})$ declare that they have no conflict of interest.

Human and Animal Rights and Informed Consent Among cited articles where one of the authors of the current report were authors, local Institutional Review Board approval was obtained and maintained for studies where human (or animal) subjects research was performed.

\section{References}

Papers of particular interest, published recently, have been highlighted as:

- Of importance

•. Of major importance

1. Lander ES, Linton LM, Birren B, Nusbaum C, Zody MC, Baldwin $\mathrm{J}$, et al. Initial sequencing and analysis of the human genome. Nature. 2001;409(6822):860-921. doi:10.1038/35057062.

2. Mattick JS. RNA regulation: a new genetics? Nat Rev Genet. 2004;5(4):316-23. doi:10.1038/nrg1321.

3. Freedman ML, Monteiro AN, Gayther SA, Coetzee GA, Risch A, Plass C, et al. Principles for the post-GWAS functional characterization of cancer risk loci. Nat Genet. 2011;43(6):513-8. doi:10. 1038/ng.840.

4. Maurano MT, Humbert R, Rynes E, Thurman RE, Haugen E, Wang $\mathrm{H}$, et al. Systematic localization of common disease-associated variation in regulatory DNA. Science. 2012;337(6099):1190-5. doi: 10.1126/science. 1222794

5. Hindorff LA, Sethupathy P, Junkins HA, Ramos EM, Mehta JP, Collins FS, et al. Potential etiologic and functional implications of genome-wide association loci for human diseases and traits. Proc Natl Acad Sci U S A. 2009;106(23):9362-7. doi:10.1073/pnas. 0903103106.
6. Consortium EP. An integrated encyclopedia of DNA elements in the human genome. Nature. 2012;489(7414):57-74. doi:10.1038/ nature11247.

7. Consortium EP, Birney E, Stamatoyannopoulos JA, Dutta A, Guigo $\mathrm{R}$, Gingeras TR, et al. Identification and analysis of functional elements in $1 \%$ of the human genome by the ENCODE pilot project. Nature. 2007;447(7146):799-816. doi:10.1038/nature05874.

8. Hangauer MJ, Vaughn IW, McManus MT. Pervasive transcription of the human genome produces thousands of previously unidentified long intergenic noncoding RNAs. PLoS Genet. 2013;9(6): e1003569. doi:10.1371/journal.pgen.1003569.

9. Mercer TR, Dinger ME, Mattick JS. Long non-coding RNAs: insights into functions. Nat Rev Genet. 2009;10(3):155-9. doi:10. 1038/nrg2521.

10. van Bakel H, Nislow C, Blencowe BJ, Hughes TR. Most "dark matter" transcripts are associated with known genes. PLoS Biol. 2010;8(5):e1000371. doi:10.1371/journal.pbio.1000371.

11. Clark MB, Amaral PP, Schlesinger FJ, Dinger ME, Taft RJ, Rinn JL, et al. The reality of pervasive transcription. PLoS Biol. 2011;9(7):e1000625. doi:10.1371/journal.pbio.1000625. discussion e1102.

12.• Mercer TR, Gerhardt DJ, Dinger ME, Crawford J, Trapnell C, Jeddeloh JA, et al. Targeted RNA sequencing reveals the deep complexity of the human transcriptome. Nat Biotechnol. 2012;30(1):99-104. doi:10.1038/nbt.2024. Combining conventional RNA-seq with RNA CaptureSeq, this study reported accurate detection and quantification of very-low abundance transcripts.

13.• Sauvageau M, Goff LA, Lodato S, Bonev B, Groff AF, Gerhardinger $\mathrm{C}$, et al. Multiple knockout mouse models reveal lincRNAs are required for life and brain development. ELife. 2013;2:e01749. doi:10. 7554/eLife.01749. This study reported in vivo genetic knockouts of eighteen lincRNAs in mouse and confirmed some lincRNAs are critical regulators of development.

14. Khalil AM, Guttman M, Huarte M, Garber M, Raj A, Rivea Morales D, et al. Many human large intergenic noncoding RNAs associate with chromatin-modifying complexes and affect gene expression. Proc Natl Acad Sci U S A. 2009;106(28):11667-72. doi:10.1073/pnas.0904715106. This study catalogued approximately three thousand lincRNAs in human cells and experimentally showed physical association for many lincRNAs with chromatin modifiers such as PRC2.

15.• Guttman M, Donaghey J, Carey BW, Garber M, Grenier JK, Munson G, et al. lincRNAs act in the circuitry controlling pluripotency and differentiation. Nature. 2011;477(7364):295300. doi:10.1038/nature10398. This study showed lincRNA genes are specific targets of embryonic stem cell transcription factors as well as lincRNA expressions and functions are critical determinants of pluripotency.

16. Klattenhoff CA, Scheuermann JC, Surface LE, Bradley RK, Fields PA, Steinhauser ML, et al. Braveheart, a long noncoding RNA required for cardiovascular lineage commitment. Cell. 2013;152(3):570-83. doi:10.1016/j.cell.2013.01. 003 .

17. Grote P, Wittler L, Hendrix D, Koch F, Wahrisch S, Beisaw A, et al. The tissue-specific lncRNA Fendrr is an essential regulator of heart and body wall development in the mouse. Dev Cell. 2013;24(2):206-14. doi:10.1016/j.devcel.2012.12.012. These two studies reported developmentally critical lncRNAs that modulate chromatin structure and function required for mouse heart development.

18. Friedlander MR, Lizano E, Houben AJ, Bezdan D, Banez-Coronel M, Kudla G, et al. Evidence for the biogenesis of more than 1,000 novel human microRNAs. Genome Biol. 2014;15(4):R57. doi:10. 1186/gb-2014-15-4-r57. 
19. Xie C, Yuan J, Li H, Li M, Zhao G, Bu D, et al. NONCODEv4: exploring the world of long non-coding RNA genes. Nucleic Acids Res. 2014;42(Database issue):D98-103. doi:10.1093/nar/gkt1222.

20. Wang ET, Sandberg R, Luo S, Khrebtukova I, Zhang L, Mayr C, et al. Alternative isoform regulation in human tissue transcriptomes. Nature. 2008;456(7221):470-6. doi:10.1038/nature07509.

21. Katayama S, Tomaru Y, Kasukawa T, Waki K, Nakanishi M, Nakamura M, et al. Antisense transcription in the mammalian transcriptome. Science. 2005;309(5740):1564-6. doi:10.1126/science. 1112009.

22. Campos EI, Reinberg D. Histones: annotating chromatin. Annu Rev Genet. 2009;43:559-99. doi:10.1146/annurev.genet.032608. 103928.

23. Mathiyalagan P, Keating ST, Du XJ, El-Osta A. Chromatin modifications remodel cardiac gene expression. Cardiovasc Res. 2014;103(1):7-16. doi:10.1093/cvr/cvu122.

24. Mondal T, Rasmussen M, Pandey GK, Isaksson A, Kanduri C. Characterization of the RNA content of chromatin. Genome Res. 2010;20(7):899-907. doi:10.1101/gr.103473.109.

25. Mathiyalagan P, Keating ST, Du XJ, El-Osta A. Interplay of chromatin modifications and non-coding RNAs in the heart. Epigenetics. 2013;9(1):101-12.

26. Ng SY, Johnson R, Stanton LW. Human long non-coding RNAs promote pluripotency and neuronal differentiation by association with chromatin modifiers and transcription factors. EMBO J. 2012;1:31(3):522-33.

27. Bartel DP. MicroRNAs: target recognition and regulatory functions. Cell. 2009;136(2):215-33. doi:10.1016/j.cell.2009.01.002.

28. Benhamed M, Herbig U, Ye T, Dejean A, Bischof O. Senescence is an endogenous trigger for microRNA-directed transcriptional gene silencing in human cells. Nat Cell Biol. 2012;14(3):266-75. doi:10. 1038/ncb2443.

29. Turchinovich A, Weiz L, Burwinkel B. Extracellular miRNAs: the mystery of their origin and function. Trends Biochem Sci. 2012;37(11):460-5. doi:10.1016/j.tibs.2012.08.003.

30. Pelechano V, Steinmetz LM. Gene regulation by antisense transcription. Nat Rev Genet. 2013;14(12):880-93. doi:10.1038/ $\operatorname{nrg} 3594$.

31.• Engreitz JM, Pandya-Jones A, McDonel P, Shishkin A, Sirokman $\mathrm{K}$, Surka $\mathrm{C}$, et al. The Xist lncRNA exploits three-dimensional genome architecture to spread across the $\mathrm{X}$ chromosome. Science. 2013;341(6147):1237973. doi:10.1126/science.1237973. This study elegantly described how XIST IncRNA spreads across the entire $X$ chromosome to mediate epigenetic silencing during $X$ chromosome Inactivation.

32. Rinn JL, Kertesz M, Wang JK, Squazzo SL, Xu X, Brugmann SA, et al. Functional demarcation of active and silent chromatin domains in human HOX loci by noncoding RNAs. Cell. 2007;129(7):1311-23. doi:10.1016/j.cell.2007.05.022.

33. Mathiyalagan P, Okabe J, Chang L, Su Y, Du XJ, El-Osta A. The primary microRNA-208b interacts with Polycomb-group protein, Ezh2, to regulate gene expression in the heart. Nucleic Acids Res. 2014;42(2):790-803. doi:10.1093/nar/gkt896. This study described for the first time a novel role for a primary microRNA transcript regulating transcription by associating with chromatin in the heart.

34. Roy-Chaudhuri B, Valdmanis PN, Zhang Y, Wang Q, Luo QJ, Kay MA. Regulation of microRNA-mediated gene silencing by microRNA precursors. Nat Struct Mol Biol. 2014;21(9):825-32. doi:10.1038/nsmb.2862. This study reported the first description of post-transcriptional regulation of microRNA-activity by precursor microRNAs.

35. Wang K, Long B, Zhou LY, Liu F, Zhou QY, Liu CY, et al. CARL IncRNA inhibits anoxia-induced mitochondrial fission and apoptosis in cardiomyocytes by impairing miR-539-dependent PHB2 downregulation. Nat Commun. 2014;5:3596. doi:10.1038/ ncomms4596.
36. Kretz M, Siprashvili Z, Chu C, Webster DE, Zehnder A, Qu K, et al. Control of somatic tissue differentiation by the long non-coding RNA TINCR. Nature. 2013;493(7431):231-5. doi:10.1038/ nature11661. This study provided mechanistic insights by which the cytoplasmic IncRNA TINCR controls epidermal differentiation through direct $m R N A$ binding.

37. Bartel DP. MicroRNAs: genomics, biogenesis, mechanism, and function. Cell. 2004;116(2):281-97.

38. Powell WT, Coulson RL, Gonzales ML, Crary FK, Wong SS, Adams S, et al. R-loop formation at Snord116 mediates topotecan inhibition of Ube3a-antisense and allele-specific chromatin decondensation. Proc Natl Acad Sci U S A. 2013;110(34):1393843. doi:10.1073/pnas.1305426110.

39. Schmitz KM, Mayer C, Postepska A, Grummt I. Interaction of noncoding RNA with the rDNA promoter mediates recruitment of DNMT3b and silencing of rRNA genes. Genes Dev. 2010;24(20): 2264-9. doi:10.1101/gad.590910. This study showed direct interaction of a ncRNA with $r R N A$ gene promoter regulating $D N A$ methylation and $r R N A$ expression.

40. Strahl BD, Allis CD. The language of covalent histone modifications. Nature. 2000;403(6765):41-5. doi:10.1038/47412.

41. Portela A, Esteller M. Epigenetic modifications and human disease. Nat Biotechnol. 2010;28(10):1057-68. doi:10.1038/nbt.1685.

42. Tsai MC, Manor O, Wan Y, Mosammaparast N, Wang JK, Lan F, et al. Long noncoding RNA as modular scaffold of histone modification complexes. Science. 2010;329(5992):689-93. doi:10.1126/ science.1192002.

43. Wang KC, Yang YW, Liu B, Sanyal A, Corces-Zimmerman R, Chen $\mathrm{Y}$, et al. A long noncoding RNA maintains active chromatin to coordinate homeotic gene expression. Nature. 2011;472(7341): 120-4. doi:10.1038/nature09819. This study reported HOTTIP IncRNA as a key locus control element that mediates H3K4me3 modification by directly binding to WDR/MLL complexes to activate transcription across HOXA genes.

44. Mohammad F, Pandey GK, Mondal T, Enroth S, Redrup L, Gyllensten U, et al. Long noncoding RNA-mediated maintenance of DNA methylation and transcriptional gene silencing. Development. 2012;139(15):2792-803. doi:10.1242/dev.079566.

45. Imamura T, Yamamoto S, Ohgane J, Hattori N, Tanaka S, Shiota K. Non-coding RNA directed DNA demethylation of Sphk1 CpG island. Biochem Biophys Res Commun. 2004;322(2):593-600. doi: 10.1016/j.bbrc.2004.07.159.

46. Yu W, Gius D, Onyango P, Muldoon-Jacobs K, Karp J, Feinberg AP, et al. Epigenetic silencing of tumour suppressor gene $\mathrm{p} 15$ by its antisense RNA. Nature. 2008;451(7175):202-6. doi:10.1038/ nature 06468.

47.• Di Ruscio A, Ebralidze AK, Benoukraf T, Amabile G, Goff LA, Terragni J, et al. DNMT1-interacting RNAs block gene-specific DNA methylation. Nature. 2013;503(7476):371-6. doi:10.1038/ nature12598. This study described a lncRNA that directly binds to and sequestrate DNMT1 from gene-specific binding to regulate genome-wide DNA methylation.

48. Bond AM, Vangompel MJ, Sametsky EA, Clark MF, Savage JC, Disterhoft JF, et al. Balanced gene regulation by an embryonic brain ncRNA is critical for adult hippocampal GABA circuitry. Nat Neurosci. 2009;12(8):1020-7. doi:10.1038/nn.2371.

49. Berghoff EG, Clark MF, Chen S, Cajigas I, Leib DE, Kohtz JD. Evf2 (Dlx6as) lncRNA regulates ultraconserved enhancer methylation and the differential transcriptional control of adjacent genes. Development. 2013;140(21):4407-16. doi:10.1242/dev.099390.

50. Maxwell SS, Pelka GJ, Tam PP, El-Osta A. Chromatin context and ncRNA highlight targets of $\mathrm{MeCP} 2$ in brain. RNA Biol. 2013;10(11):1741-57. doi:10.4161/rna.26921.

51. Gupta RA, Shah N, Wang KC, Kim J, Horlings HM, Wong DJ, et al. Long non-coding RNA HOTAIR reprograms chromatin state 
to promote cancer metastasis. Nature. 2010;464(7291):1071-6. doi: 10.1038/nature08975.

52. Li D, Feng J, Wu T, Wang Y, Sun Y, Ren J, et al. Long intergenic noncoding RNA HOTAIR is overexpressed and regulates PTEN methylation in laryngeal squamous cell carcinoma. Am J Pathol. 2013;182(1):64-70. doi:10.1016/j.ajpath.2012.08.042.

53. Arab K, Park YJ, Lindroth AM, Schafer A, Oakes C, Weichenhan $\mathrm{D}$, et al. Long noncoding RNA TARID directs demethylation and activation of the tumor suppressor TCF21 via GADD45A. Mol Cell. 2014;55(4):604-14. doi:10.1016/j.molcel.2014.06.031.

54. Arab K, Smith LT, Gast A, Weichenhan D, Huang JP, Claus R, et al. Epigenetic deregulation of TCF21 inhibits metastasis suppressor KISS1 in metastatic melanoma. Carcinogenesis. 2011;32(10): 1467-73. doi:10.1093/carcin/bgr138.

55. Zhao J, Sun BK, Erwin JA, Song JJ, Lee JT. Polycomb proteins targeted by a short repeat RNA to the mouse X chromosome. Science. 2008;322(5902):750-6. doi:10.1126/science.1163045.

56. Hacisuleyman E, Goff LA, Trapnell C, Williams A, Henao-Mejia J, Sun $\mathrm{L}$, et al. Topological organization of multichromosomal regions by the long intergenic noncoding RNA Firre. Nat Struct Mol Biol. 2014;21(2):198-206. doi:10.1038/nsmb.2764.

57.• Quinn JJ, Ilik IA, Qu K, Georgiev P, Chu C, Akhtar A, et al. Revealing long noncoding RNA architecture and functions using domain-specific chromatin isolation by RNA purification. Nat Biotechnol. 2014;32(9):933-40. doi:10.1038/nbt.2943. This study reported a novel assay that targets individual domains within IncRNA to reveal IncRNA architecture inside chromatin.

58. Takeuchi JK, Lou X, Alexander JM, Sugizaki H, Delgado-Olguin $\mathrm{P}$, Holloway AK, et al. Chromatin remodelling complex dosage modulates transcription factor function in heart development. Nat Commun. 2011;2:187. doi:10.1038/ncomms1187.

59. Olson EN. Gene regulatory networks in the evolution and development of the heart. Science. 2006;313(5795):1922-7. doi:10.1126/ science.1132292.

60. Zhang CL, McKinsey TA, Chang S, Antos CL, Hill JA, Olson EN. Class II histone deacetylases act as signal-responsive repressors of cardiac hypertrophy. Cell. 2002;110(4):479-88.

61. Mathiyalagan P, Chang L, Du XJ, El-Osta A. Cardiac ventricular chambers are epigenetically distinguishable. Cell Cycle. 2010;9(3): 612-7.

62. Backs J, Olson EN. Control of cardiac growth by histone acetylation/deacetylation. Circ Res. 2006;98(1):15-24. doi:10.1161/01. RES.0000197782.21444.8f.

63. Chang L, Kiriazis H, Gao XM, Du XJ, El-Osta A. Cardiac genes show contextual SWI/SNF interactions with distinguishable gene activities. Epigenetics. 2011;6(6):760-8.

64. Hang CT, Yang J, Han P, Cheng HL, Shang C, Ashley E, et al. Chromatin regulation by $\mathrm{Brg} 1$ underlies heart muscle development and disease. Nature. 2010;466(7302):62-7. doi:10.1038/ nature09130.

65. Kong Y, Tannous P, Lu G, Berenji K, Rothermel BA, Olson EN, et al. Suppression of class I and II histone deacetylases blunts pressure-overload cardiac hypertrophy. Circulation. 2006;113(22): 2579-88. doi:10.1161/CIRCULATIONAHA.106.625467.

66. Xie M, Kong Y, Tan W, May H, Battiprolu PK, Pedrozo Z, et al. HDAC inhibition blunts ischemia/reperfusion Injury by inducing cardiomyocyte autophagy. Circulation. 2014. doi:10.1161/ CIRCULATIONAHA.113.002416.

67. Rafehi H, Balcerczyk A, Lunke S, Kaspi A, Ziemann M, Kn H, et al. Vascular histone deacetylation by pharmacological HDAC inhibition. Genome Res. 2014. doi:10.1101/gr.168781.113.

68. Han P, Li W, Lin CH, Yang J, Shang C, Nuernberg ST, et al. A long noncoding RNA protects the heart from pathological hypertrophy. Nature. 2014. doi:10.1038/nature13596.
69. Luther HP. Role of endogenous antisense RNA in cardiac gene regulation. J Mol Med (Berl). 2005;83(1):26-32. doi:10.1007/ s00109-004-0613-5.

70. Boheler KR, Chassagne C, Martin X, Wisnewsky C, Schwartz K. Cardiac expressions of alpha- and beta-myosin heavy chains and sarcomeric alpha-actins are regulated through transcriptional mechanisms. Results from nuclear run-on assays in isolated rat cardiac nuclei. J Biol Chem. 1992;267(18):12979-85.

71. Podlowski S, Bramlage P, Baumann G, Morano I, Luther HP. Cardiac troponin I sense-antisense RNA duplexes in the myocardium. J Cell Biochem. 2002;85(1):198-207.

72. Lee JH, Gao C, Peng G, Greer C, Ren S, Wang Y, et al. Analysis of transcriptome complexity through RNA sequencing in normal and failing murine hearts. Circ Res. 2011;109(12):1332-41. doi:10. 1161/CIRCRESAHA.111.249433.

73. Ounzain S, Micheletti R, Beckmann T, Schroen B, Alexanian M, Pezzuto I, et al. Genome-wide profiling of the cardiac transcriptome after myocardial infarction identifies novel heart-specific long noncoding RNAs. Eur Heart J. 2014. doi:10.1093/eurheartj/ehu180.

74. Kumarswamy R, Bauters C, Volkmann I, Maury F, Fetisch J, Holzmann A, et al. Circulating long noncoding RNA, LIPCAR, predicts survival in patients with heart failure. Circ Res. 2014;114(10):1569-75. doi:10.1161/CIRCRESAHA.114.303915.

75. Helgadottir A, Thorleifsson G, Manolescu A, Gretarsdottir S, Blondal T, Jonasdottir A, et al. A common variant on chromosome 9 p21 affects the risk of myocardial infarction. Science. 2007;316(5830):1491-3. doi:10.1126/science.1142842.

76. Visel A, Zhu Y, May D, Afzal V, Gong E, Attanasio C, et al. Targeted deletion of the 9p21 non-coding coronary artery disease risk interval in mice. Nature. 2010;464(7287):409-12. doi:10.1038/ nature08801.

77. Kotake Y, Nakagawa T, Kitagawa K, Suzuki S, Liu N, Kitagawa M, et al. Long non-coding RNA ANRIL is required for the PRC2 recruitment to and silencing of p15(INK4B) tumor suppressor gene. Oncogene. 2011;30(16):1956-62. doi:10.1038/onc.2010.568.

78. Wang K, Liu F, Zhou LY, Long B, Yuan SM, Wang Y, et al. The long noncoding RNA CHRF regulates cardiac hypertrophy by targeting miR-489. Circ Res. 2014;114(9):1377-88. doi:10.1161/ CIRCRESAHA.114.302476.

79. Ng WA, Grupp IL, Subramaniam A, Robbins J. Cardiac myosin heavy chain mRNA expression and myocardial function in the mouse heart. Circ Res. 1991;68(6):1742-50.

80. Rundell VL, Manaves V, Martin AF, de Tombe PP. Impact of betamyosin heavy chain isoform expression on cross-bridge cycling kinetics. Am J Physiol Heart Circ Physiol. 2005;288(2):H896903. doi:10.1152/ajpheart.00407.2004

81. Reiser PJ, Portman MA, Ning XH, Schomisch MC. Human cardiac myosin heavy chain isoforms in fetal and failing adult atria and ventricles. Am J Physiol Heart Circ Physiol. 2001;280(4):H1814 20.

82. Miyata S, Minobe W, Bristow MR, Leinwand LA. Myosin heavy chain isoform expression in the failing and nonfailing human heart. Circ Res. 2000;86(4):386-90.

83. Lowes BD, Minobe W, Abraham WT, Rizeq MN, Bohlmeyer TJ, Quaife RA, et al. Changes in gene expression in the intact human heart. Downregulation of alpha-myosin heavy chain in hypertrophied, failing ventricular myocardium. J Clin Invest. 1997;100(9):2315-24. doi:10.1172/JCI119770.

84. Gupta MP. Factors controlling cardiac myosin-isoform shift during hypertrophy and heart failure. J Mol Cell Cardiol. 2007;43(4):388403. doi:10.1016/j.yjmcc.2007.07.045.

85. Mahdavi V, Chambers AP, Nadal-Ginard B. Cardiac alpha- and beta-myosin heavy chain genes are organized in tandem. Proc Natl Acad Sci U S A. 1984;81(9):2626-30.

86. van Rooij E, Quiat D, Johnson BA, Sutherland LB, Qi X, Richardson JA, et al. A family of microRNAs encoded by myosin 
genes governs myosin expression and muscle performance. Dev Cell. 2009;17(5):662-73. doi:10.1016/j.devcel.2009.10.013.

87. Montgomery RL, Hullinger TG, Semus HM, Dickinson BA, Seto AG, Lynch JM, et al. Therapeutic inhibition of miR-208a improves cardiac function and survival during heart failure. Circulation. 2011;124(14):1537-47. doi:10.1161/CIRCULATIONAHA.111. 030932.

88. Callis TE, Pandya K, Seok HY, Tang RH, Tatsuguchi M, Huang ZP, et al. MicroRNA-208a is a regulator of cardiac hypertrophy and conduction in mice. J Clin Invest. 2009;119(9):2772-86. doi:10. 1172/JCI36154.

89. Corsten MF, Dennert R, Jochems S, Kuznetsova T, Devaux Y, Hofstra L, et al. Circulating MicroRNA-208b and MicroRNA-499 reflect myocardial damage in cardiovascular disease. Circ Cardiovasc Genet. 2010;3(6):499-506. doi:10.1161/ CIRCGENETICS.110.957415.

90. Xiao J, Shen B, Li J, Lv D, Zhao Y, Wang F, et al. Serum microRNA-499 and microRNA-208a as biomarkers of acute myocardial infarction. Int J Clin Exp Med. 2014;7(1):136-41.

91. Luther HP, Podlowski S, Hetzer R, Baumann G. Analysis of sense and naturally occurring antisense transcripts of myosin heavy chain in the human myocardium. J Cell Biochem. 2001;80(4):596-605. doi:10. 1002/1097-4644(20010315)80:4<596::AID-JCB1014>3.0.CO;2-Y.

92. Haddad F, Bodell PW, Qin AX, Giger JM, Baldwin KM. Role of antisense RNA in coordinating cardiac myosin heavy chain gene switching. J Biol Chem. 2003;278(39):37132-8. doi:10.1074/jbc. M305911200.
93. Haddad F, Qin AX, Bodell PW, Jiang W, Giger JM, Baldwin KM. Intergenic transcription and developmental regulation of cardiac myosin heavy chain genes. Am J Physiol Heart Circ Physiol. 2008;294(1):H29-40. doi:10.1152/ajpheart.01125.2007.

94. Haddad F, Jiang W, Bodell PW, Qin AX, Baldwin KM. Cardiac myosin heavy chain gene regulation by thyroid hormone involves altered histone modifications. Am J Physiol Heart Circ Physiol. 2010;299(6):H1968-80. doi:10.1152/ajpheart.00644.2010.

95. Haddad F, Qin AX, Bodell PW, Zhang LY, Guo H, Giger JM, et al. Regulation of antisense RNA expression during cardiac MHC gene switching in response to pressure overload. Am J Physiol Heart Circ Physiol. 2006;290(6):H2351-61. doi:10.1152/ ajpheart.01111.2005.

96. Monteys AM, Spengler RM, Wan J, Tecedor L, Lennox KA, Xing $\mathrm{Y}$, et al. Structure and activity of putative intronic miRNA promoters. RNA. 2010;16(3):495-505. doi:10.1261/rna.1731910.

97. Grueter CE, van Rooij E, Johnson BA, DeLeon SM, Sutherland LB, Qi X, et al. A cardiac microRNA governs systemic energy homeostasis by regulation of MED13. Cell. 2012;149(3):671-83. doi:10.1016/j.cell.2012.03.029.

98. Modarresi F, Faghihi MA, Lopez-Toledano MA, Fatemi RP, Magistri M, Brothers SP, et al. Inhibition of natural antisense transcripts in vivo results in gene-specific transcriptional upregulation. Nat Biotechnol. 2012;30(5):453-9. doi:10.1038/nbt.2158. This study reported pharmacological inhibition of a lncRNA in vivo to upregulate specific pattern of gene expression by modulating chromatin structure. 